\title{
18 Reviving the Hexagon for the University Library on the Luminy Campus of Aix- Marseille University
}

\begin{abstract}
The Hexagone Bibliothèque Universitaire de Sciences de Luminy, Aix-Marseille Université / Hexagon University Library at the Luminy campus of the Aix-Marseille University is located near the entrance to the Calanques National Park on the outskirts of Marseille in France. The Hexagon was the university restaurant from the early 1960 s and regarded as the heart of the campus. It was closed early this century when a new restaurant was built. It became famous for its graffiti and housed many stunning murals. Opération Campus, a national programme for campus redevelopment, retained the Luminy campus for its research potential and the development plan included use of the hexagonal building to house the new library and several other services to the university community. A local architect was chosen to reinterpret the Hexagon and adapt its reuse to the highest international standards. Following constructive dialogue between librarians, the architect and the university consulting architect, the new Luminy Hexagon Library was designed and opened in September 2018. It combines the comfort of a social place on campus with the latest equipment for supporting learning, teaching and research. The chapter describes how librarians and architects worked together to reactivate the Hexagon as the heart of the campus.
\end{abstract}

Keywords: Library buildings - Design and construction; Restaurants - Remodelling for other use; Academic libraries - France

\section{Introduction}

The Hexagone Bibliothèque Universitaire de Sciences de Luminy, Aix-Marseille Université/Hexagon University Library at the Luminy campus of the Aix-Marseille University (Figure 1) is located in the south of Marseille, the second largest city in France. Located at the gates of the magnificent Calanques, the Luminy campus contains amongst other treasures an old country house, seat of the Centre International de Rencontres Mathématiques (CIRM) and is renowned for the beauty of its hills and bushland. The history of the Luminy estate began around 1005. Paul Cyprien Fabre became the sole owner in the $20^{\text {th }}$ century, and he renovated the park, replanting trees and opening a road giving access to the waterways. In 1945, Luminy became public property with various uses until 1966

Ә Open Access. (2021 Samuel Lespets and Rémy Marciano, published by De Gruyter. (cc)BY-NC-ND This work is licensed under the Creative Commons Attribution-NonCommercial-NoDerivatives 4.0 International License. https://doi.org/10.1515/9783110679663-019 


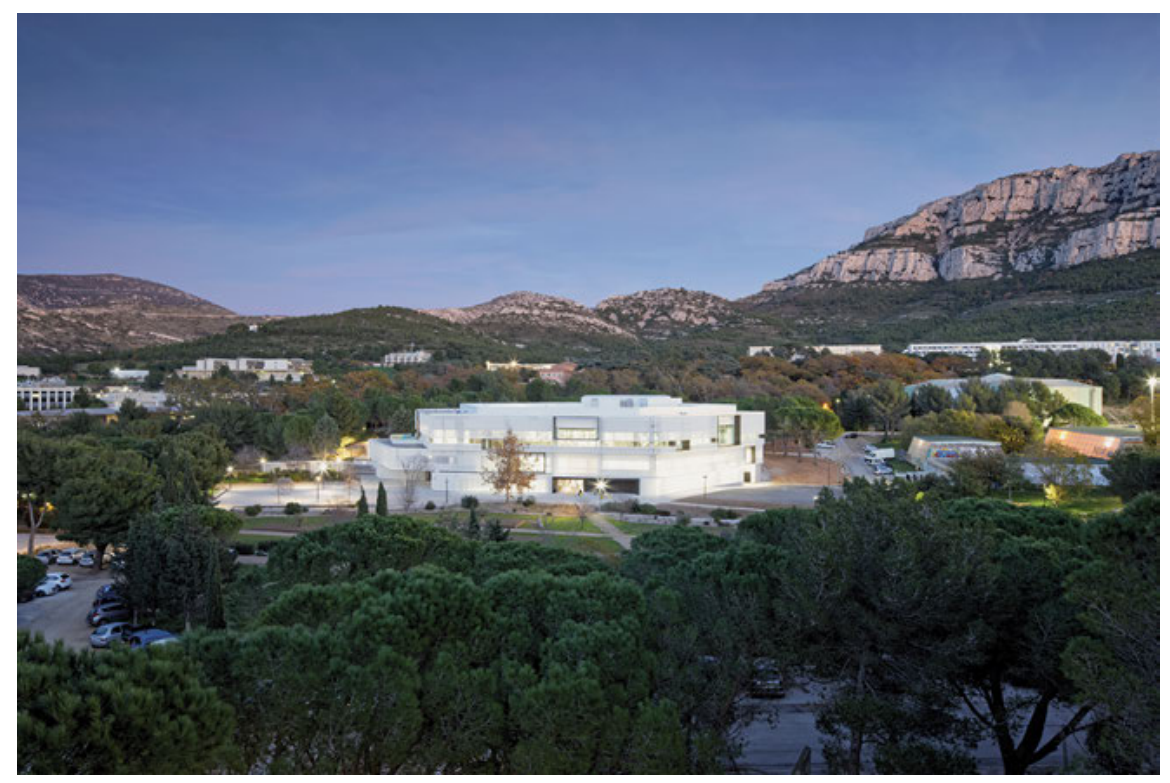

Fig. 1: View of the Hexagon in Luminy. () Takuji Shimmura.

\section{Facts and Figures}

Name: Hexagone Bibliothèque Universitaire de Sciences de Luminy/Hexagon University Library Luminy, Aix-Marseille Université

Address: Case 901, 172 Avenue de Luminy, 13009 Marseille, France

Website: https://bu.univ-amu.fr/bu-luminy

Opening: September 2018

Builder: Bouygues Bâtiments Sud Est http://www.bouygues-batiment-sud-est.fr/

Architects: 1966: René Egger; 2018: Rémy Marciano Agence Rémy Marciano_Architecte http://www.remy-marciano.com

Gross floor area: $7,000 \mathrm{~m}^{2}$ (building)

Main floor space: $2,500 \mathrm{~m}^{2}$ (library space)

Collection size: 53,000

Staff: 11

Workstations: 700

Building costs: $€ 18,500,000$

and the creation of the Luminy university campus with a science faculty and a university residence, to cope with the development of new disciplines and the significant increase in the number of students. 
Today, the Luminy campus is the site for the science and technology faculties of Aix-Marseille Université (AMU): sports sciences, life sciences, chemistry and physics, as well as a polytechnic and an institute of technology which come under the AMU umbrella. AMU is the largest multidisciplinary French-speaking university, with 80,000 students and nearly 8,000 staff on 5 large campuses of international standards. Connected to AMU are many of the largest French research organisations, including the Institut National de la Santé et de la Recherche Médicale (INSERM), Centre National de la Recherche Scientifique (CNRS), and others. Not part of AMU is the Kedge Business School connected to the chamber of commerce and industry of Marseille, the École Supérieure d'Art et de Design de Marseille Méditerranée (ESADMM), and the École Nationale Supérieure d'Architecture de Marseille (ENSAM) connected to the French Ministry of Culture. There are approximately 5,000 AMU students, staff and researchers on the site, but when the other educational organisations are taken into account, the potential number of users rises to approximately 15,000. To complete the picture, Luminy is the gate of the Calanques National Park, one of the main tourist attractions in the area. People come to the library to relax and read a newspaper after hiking in the Calanques.

\section{The New Hexagon}

The Hexagon was one of the first buildings on the Luminy campus in 1966. It was designed by the architect René Egger to accommodate the university restaurant and located close to the university student residences (Figure 2).

The first library was situated near the teaching and research buildings. The campus layout changed considerably over the years. Many teaching and research buildings emerged with the development of new academic disciplines and were built mainly on the northern part of the campus. A new restaurant was built closer to the central campus and the teaching facilities and the Hexagon housed offices until it was closed in 2010.

From 2008, the French government launched the national programme Opération Campus to create large university centres, to accelerate their development and to assist French universities to progress in the Shanghai and other similar international rankings. The Luminy campus was selected for its potential in research in the life sciences and sports disciplines. The university recruited a consulting architect to develop a master plan for the campus which would connect all the networks and buildings with both new construction and restoration. A project to create a new Library and Learning Centre to replace the old library and bring 


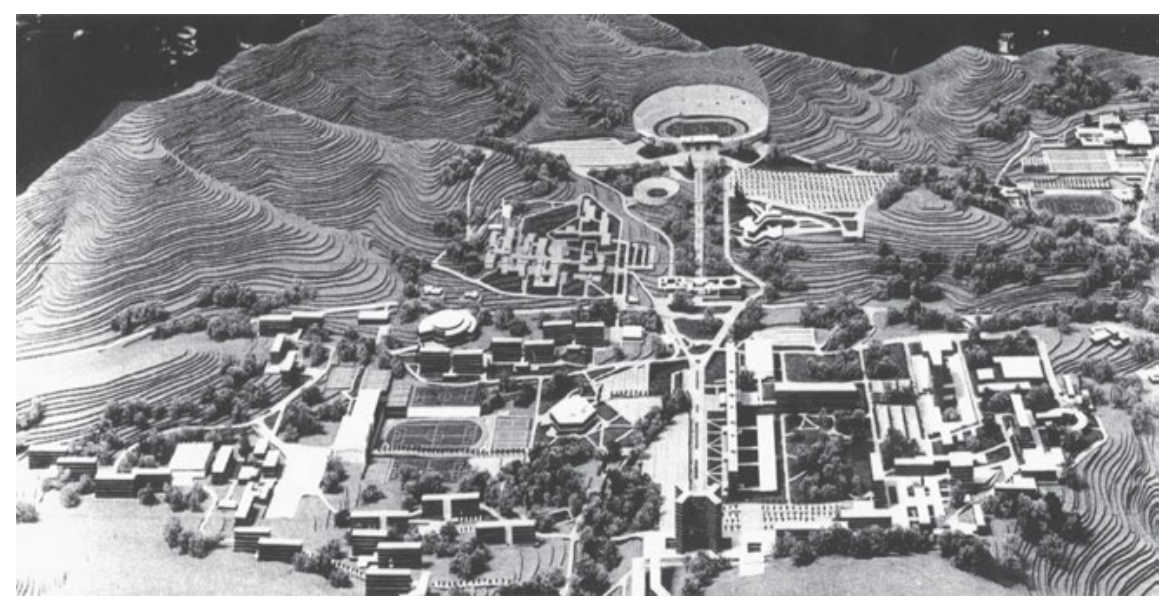

Fig. 2: Model of the Luminy campus project. () René Egger.

together resources and support services for students and teachers alike emerged from the process. The decision to keep and restore the Hexagon was made as it was deemed an iconic building of René Egger.

The Hexagon formerly contained the restaurant and an amphitheatre. Former students, some of whom became teachers, researchers or staff, remember past times nostalgically and constitute the living memory of the campus. Numerous festivals, concerts and celebrations were organised over the years in the Hexagon making it of key importance to students as the heart of the campus. Lack of use led to a slow and long demise for the Hexagon which became dilapidated (Figure 4). Some areas of the ground floor continued to be occupied by offices linked to the Centre Régional des Oeuvres Universitaires et Scolaires (CROUS), the organisation responsible for management of university housing, but the main areas were closed and walled up. The youth of the southern districts of Marseille turned it into a graffiti mecca. Can the quality of the frescoes be explained by the immediate proximity of the School of Fine Arts? The fact is that many huge frescoes gradually covered the walls of the abandoned building (Figure 3). The place was also used by squatters and resulted in a tragic event. A student from the School of Fine Arts fell from the roof of the building that was closed to the public, during what seems to have been a drunken clandestine party. The University administrators asked the fire brigade at Luminy to take over the management of the building and to secure it. The firefighters used the building, which was particularly complex in its spatial organisation and circulation, to carry out their rescue exercises and training. The situation continued until rehabilitation work began in the spring of 2017. 


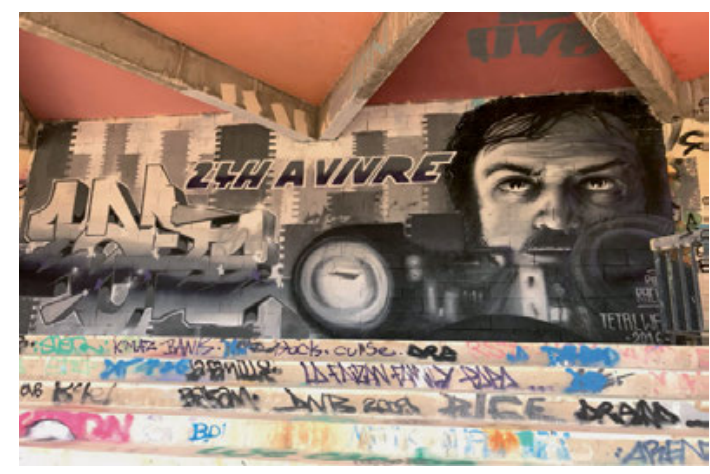

Fig. 3: One of the frescoes that covered the Hexagon before its restoration. (c) Bertrand Mallet.

\section{Preparation for the New Library}

Firstly, with the help of the consulting architect, a library team prepared an initial brief with a list of requirements taking into account the defects of the old library and perceived student needs particularly regarding group work. The library team carried out surveys of users and collection needs. The aim of the work was to prepare and organise the services for offer in the new library. The specific goals were to:

- Gain a better understanding of the actual and potential users of the library to fit out the future library and offer services in the Hexagon that would meet users' expectations

- Improve the way users are welcomed to the library

- Accustom the team to the concept of the library as a learning centre with up-to-date facilities and equipment including RFID technology, self-service machines, automated room bookings and electronic devices.

Different initiatives were launched:

- A user study. 200 observations were conducted by the library staff over six months. The main outcome was that space use was diverse with varying types of use on different occasions. Students worked in the study areas mainly on their own materials, alone or in small groups although they also relaxed. Some students were comfortable with noise; others used noise-cancelling devices. In the informal spaces, some work activities were carried out. More photocopiers and PCs were required. Between $50 \%$ and $70 \%$ of users worked individually on computers; the rest worked in groups of two. The five group 
study rooms in the old library were clearly insufficient and more whiteboards and flipcharts were needed.

- Analysis of the booking management system for group rooms. It revealed that $75 \%$ of bookings were for four people or fewer.

- Interviews and focus groups which enabled users to define the ideal library. Users wanted: quiet study spaces, numerous group study rooms, sufficient power outlets, a wide-ranging collection and long opening hours.

- An online survey of circulation desk activity. It showed the number and distribution of transactions daily and weekly, and whether library staff needed to leave the desk to provide assistance (33\% of instances) and identified the purpose of the interaction. The following major areas of need were identified:

- $21 \%$ devices or photocopying

- $16.5 \%$ information retrieval

- $\quad 12.5 \%$ lending of electronic devices

- $11.5 \%$ orientation on campus (the library was located next to the main entrance)

- $\quad 11.5 \%$ services.

The library team concluded that there was a need for well-maintained photocopiers and computers, a more central location for the library on campus, a new service offering electronic devices for loan and a relocation of the information and circulation desk. Other activities supplemented the various studies undertaken. Public presentations were made on the project; whiteboards were placed in the library and sought unrestricted and innovative expressions on library needs; and an academic study carried out by a colleague investigated student perceptions of librarians' work.

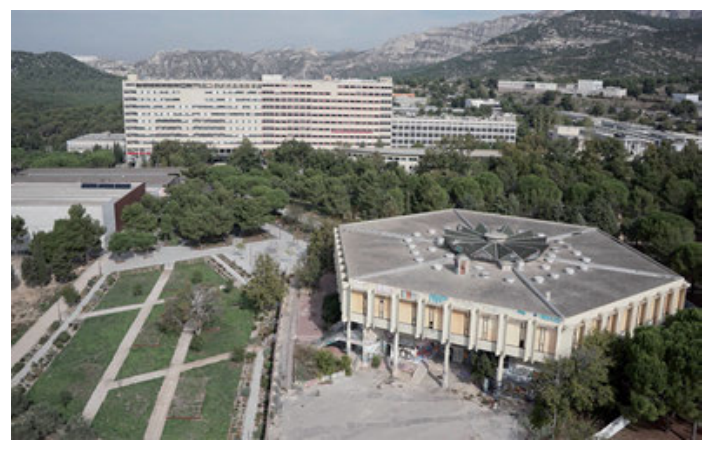

Fig. 4: The Hexagon before restoration. (C) Bertrand Mallet.

The wide-ranging approach made it possible to refine and improve the brief of requirements by understanding the expectations of users and integrating suggestions received and conclusions drawn from the surveys. The entire library team 
was involved in the preparatory work and each team member was able to imagine her/himself in the new building and to prepare for new service provision. Lastly, it enabled the public, whose opinions were widely solicited, to become better acquainted with the project and to express their expectations and wishes.

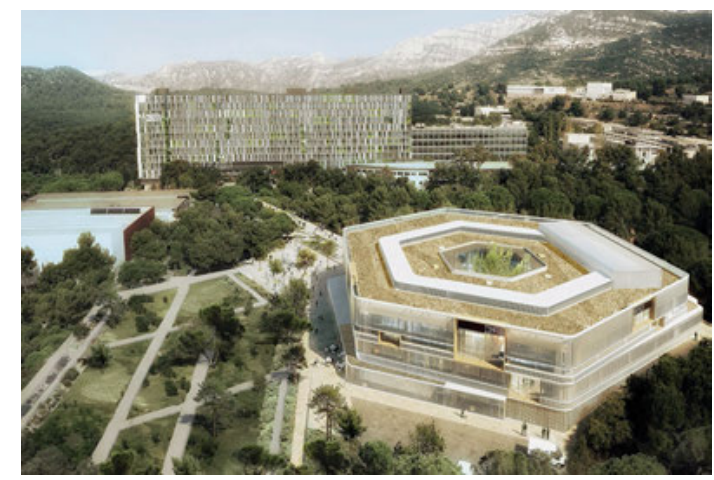

Fig. 5: Architect's view after restoration. (C) Rémy Marciano.

\section{The Sequence of Events}

A brief was prepared outlining the various requirements but there was no concrete expression in space. The preparatory work was carried out by the library in parallel with other departments that would come together in the Hexagon, with the consulting architect and his team playing the role of coordinators in the project. The different activities planned for the future building were a language learning centre, the international relations service, the university counselling service, the sports service and the student experience and disability office. Several meetings brought out the need to make room in the future library and learning centre for student activities, in particular through spaces to hold student events, facilities for student associations and work areas accessible without reservation. The entire student area has been compartmentalised to allow 24-hour access, even when the rest of the building is closed. The campus has been complemented by a snack bar, a photocopy centre and offices for visitors or staff working from home. Various facilities were intended to host large-scale events, whether cultural or academic in nature. They included an auditorium with video and audio capability, a video-conference room, a shared meeting room for services integrated into the learning centre, an exhibition area and a common kitchen - a highly strategic place! In summary, the programme was built around three notions: a place for resources, a hub for services and an area for training. 


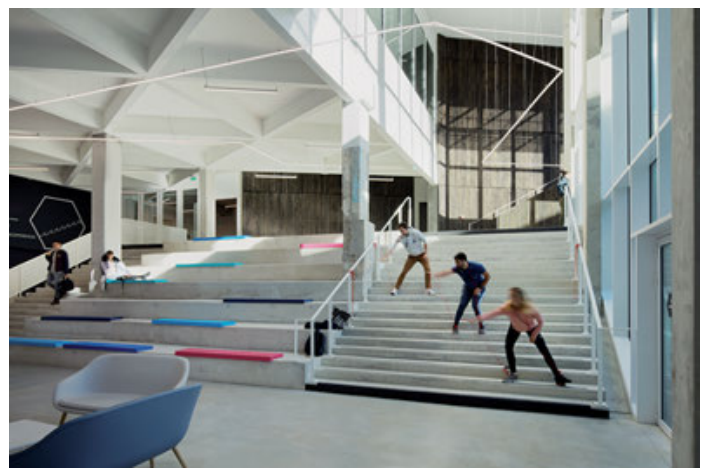

Fig. 6: Lobby and bleachers/tiers. (C) Takuji Shimmura.

The full details of building requirements were finalised during 2014 and called Campus Core. A tender was put out based on the brief. Competitive dialogue and exchanges began with the various consortia that had responded to the tender. For a year and a half, the consortia submitted proposals for the development of the Hexagon at regular intervals, including plans and architectural views. For each submission, the University's consulting architect's team brought together all the stakeholders, including library staff, to contribute their opinions and comments on the proposals.

The teams did not know the candidates' names, but all could see that between the beginning and end of the workshop sessions, some consortia had changed architects, demonstrating appropriate responses to the feedback given in the workshops. In February 2016, the partnership contract was signed with the selected consortium, Bouygues Bâtiments Sud-Est, by the President of the University. Following the signing, a final improvement phase of the project continued until spring 2017, when construction work began on the Hexagon. Work continued at an intense pace until the opening of the Hexagon in its new form in September 2018. Following finalisation of the partnership contract, the exchanges with the chosen architect, Rémy Marciano, became both more direct and concrete. Rémy Marciano is a local architect and had been a student user of the former university restaurant. Undoubtedly, his background helped him to understand the project issues and make the most of the building's strengths and weaknesses (Figure 5). Following a constructive dialogue between the librarians, the selected architect and the university consulting architect, the new Luminy Hexagon Library and Learning Centre was opened in September 2018 (Figure 6). 


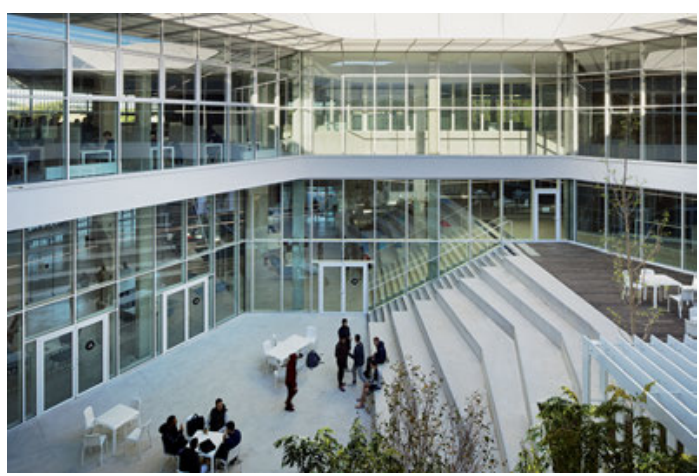

Fig. 7: The patio. (C) Takuji

Shimmura.

\section{Collaboration and Impact of the Building}

The collaboration between the librarians and the architect was extremely productive. The dialogue was contained within the framework of the architectural programme signed with the builder, which served as a contract. Within the framework, and through the intermediary of the consulting architect, Rémy Marciano was receptive to the suggestions and comments of the library team. Three significant examples can be cited.

One of the first building layouts offered three distinct areas: collections, study areas and relaxation areas. Following the team's request to combine the different spaces, the architect reworked the plan to propose a balance between shelving and study tables and more comfortable seats, such as armchairs and sofas. The result is an orderly and harmonious blending and integration of the spaces.

The librarians' observations on the use of group study rooms led them to propose rooms that vary in capacity from two to sixteen people with a variety of seating ranging from comfortable low seats for a long stay through classic seats for study periods to high stools for short meetings. The library team suggested a range of equipment including interactive screens, simple screens or whiteboards with no screens. The architect noted the requirements and was able to take advantage of the space to arrange the group study rooms to make the most of the available surface area and the light and its orientation.

Finally, the choice of furniture was based on a fluid exchange between the architect and the library team. The library team used Pinterest boards to provide the architect with a range of furniture choices. Various exchanges led to a selection of furniture that was both functional and elegant and perfectly integrated into the new library. Some emblematic and spectacular elements, such as hex- 
agonal honeycomb-shaped alcove walls, were designed by the architect and custom-made (Figure 8).

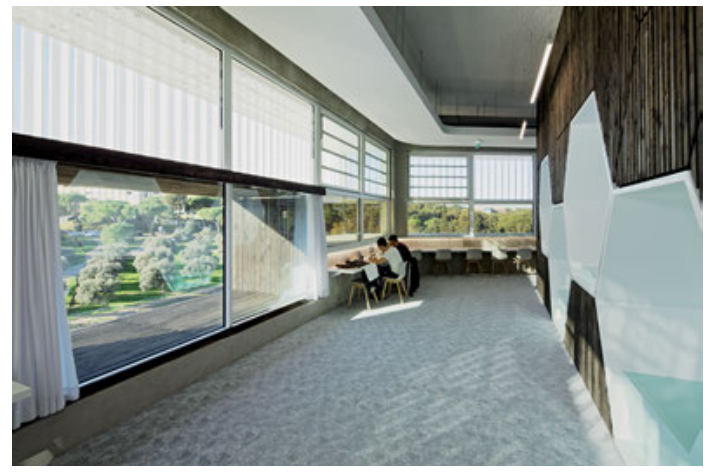

Fig. 8: Hexagonal honeycombshaped alcove walls relate to the building landscape. (C) Takuji Shimmura.

A Libqual satisfaction survey, conducted throughout the university library network at the end of 2018 highlighted the high level of user satisfaction with the new library. To evaluate the reception of the building by users, and its impact, objectively and independently, a student trainee curator conducted a study using User Experience (UX) design tools, including observations of library users and short interviews with users. The study in the spring of 2019 confirmed the excellent feedback from users on the library and contributed to an accurate picture of how users use the library. The most commonly undertaken activities were found to include working on personal print materials, using a computer, relaxing and chatting. The most frequented areas were the study carrels in semi-open spaces for individual or paired work, and the group study rooms. The conclusions of the survey reflected the findings of the earlier studies done in preparation for the renovation, namely, that the most frequent activity in the study spaces was working with personal print materials. However, the area includes relaxation spaces and surprisingly, while the areas were most frequently used for chatting, over one third of activities undertaken related to work.

The survey revealed room for improvement: one bone of contention was noise, about which many users complained, despite the availability of group study rooms elsewhere in the building. There are 20 group study rooms in the library and 20 in other parts of the building. Following the survey, a working group was established to examine the noise issue. As a result, the introduction of clear signage and the reorganisation of library spaces establishing a silent zone where chatting is not tolerated, and a quiet zone where it is possible to talk at a moderate level, partially resolved the problem. 
The library offers 700 workstations supporting different ways of working: 140 are located in small work areas accommodating two people; 20 group study rooms of varying sizes accommodate groups of up to 16 people; 150 workstations for individual use are located at the periphery with a view onto pine trees; 160 are located at large library tables; 250 are placed with informal seating of sofas and comfortable chairs; and a training room can host 25 people.

The Hexagon library and learning centre combines the comfort of a living room and a social place on campus and it has become the central focus of the campus, with equipment for supporting learning, teaching and research. It received in November 2018, three months after it opened, the award of Grand Prix Livres Hebdo de l'espace intérieur from the main national book industry's professional magazine. Attendance increased by 30\%. Much has been written about the transformation (Feil 2020; Schoof 2019; Shimmura 2019; Wu 2019). The Hexagon has truly reverted to the campus heart it had been when it was built as a university restaurant.

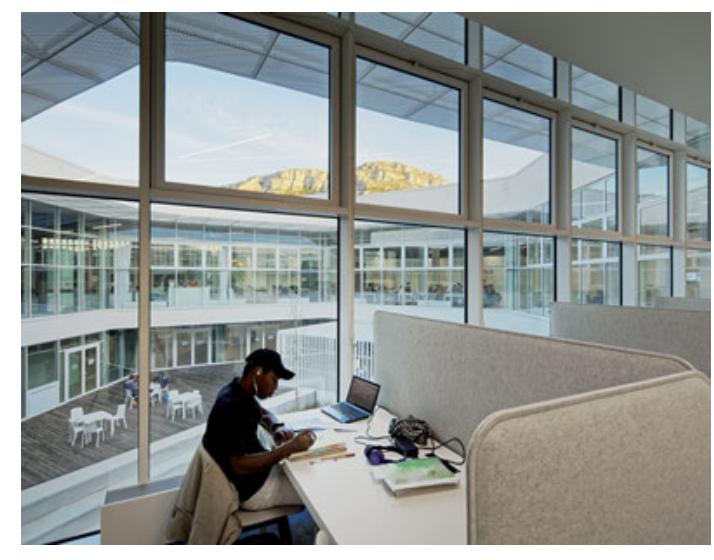

Fig. 9: Study carrels, patio and view of Mount Puget. (C) Takuji Shimmura.

\section{The Architect's Approach}

The project was developed from the competition phase under a Public Private Partnership through Bouygues Construction. The relationship with AMU was excellent throughout the operation: the stakeholders contributed as volunteers to discussions throughout the planning and construction phases and have been a driving force in the life of the completed building.

Renovating the Hexagon was an ambitious project from the outset. Providing a variety of uses was hindered by the depth of the structure that prevented 
sufficient lighting with only the second and top floors having the capacity to be put to worthwhile use. The recess in the central patio (Figure 7) and a breakout connecting the high and low halls provides a breath of fresh air and creates a momentous space in the building. The central, outdoor, open space is a natural and playful extension. Organised with bleacher or tiered seating in line with the natural topography of the site, the space can become an agora, a place for gathering and relaxation with the recess providing the necessary light for the different areas of the building (Figure 6).

Clearing part of the first slab in the lower part of the ground floor enabled the provision of a more generous space in line with the project goals. Some functions are provided in a ring around the existing building and in a more simplistic way. Rather like crowns, the functional strips form a strong connection to the topography and create, above them, terraces to be occupied by the students.

The architects conceived the transformation of the Hexagon into a learning centre as a flexible and attractive building for the Aix-Marseille university campus of Luminy. It would become a contemporary place for students to live, exchange and share with the informality of the spaces encouraging ownership. It is a sublime, rocky and sculpted site where the wild landscape of the Calanques invites itself into the campus and offers a setting conducive to reading and daydreaming with the enchanting scent of a pine forest.

The project constituted a major transformation of the former university restaurant into a library. The intention was to show and stage the transformations of the building with remnants of the former building, including the re-casting and underpinning. The Hexagon was composed of six building sections each separated by a loadbearing wall. The piercing of the patio and the extension on three sides of the building allowed a structural girdle and the elimination of loadbearing walls. Modern archaeology and the 1960s concrete of the existing building, preserved and transformed, reveal traces of the past, the hand of man and the passage of time. The materials used are rediscovered and imbued with new meaning. A milky white skin envelops the Hexagon and its extensions and creates a new landscape sculpted in and echoing the nearby limestone rock, where porosity and transparency let light generously penetrate the spaces. The topography of the site is restaged in a stepped stratification from the reception area to the patio in the heart of the building (Figures 7 and 10).

The spaces are generous and can be appropriated by all. The Hexagon is a place of study, but above all a place of life, of knowledge-sharing, of communication, of sociability and of openness to the world. The Hexagon includes a large university library, a projection room, an open space, a café and student services. The transitional spaces, patios, terraces, steps and corridors are designed as real places of welcome, meeting and relaxation (Figures 6, 7 and 9). The more informal spaces 


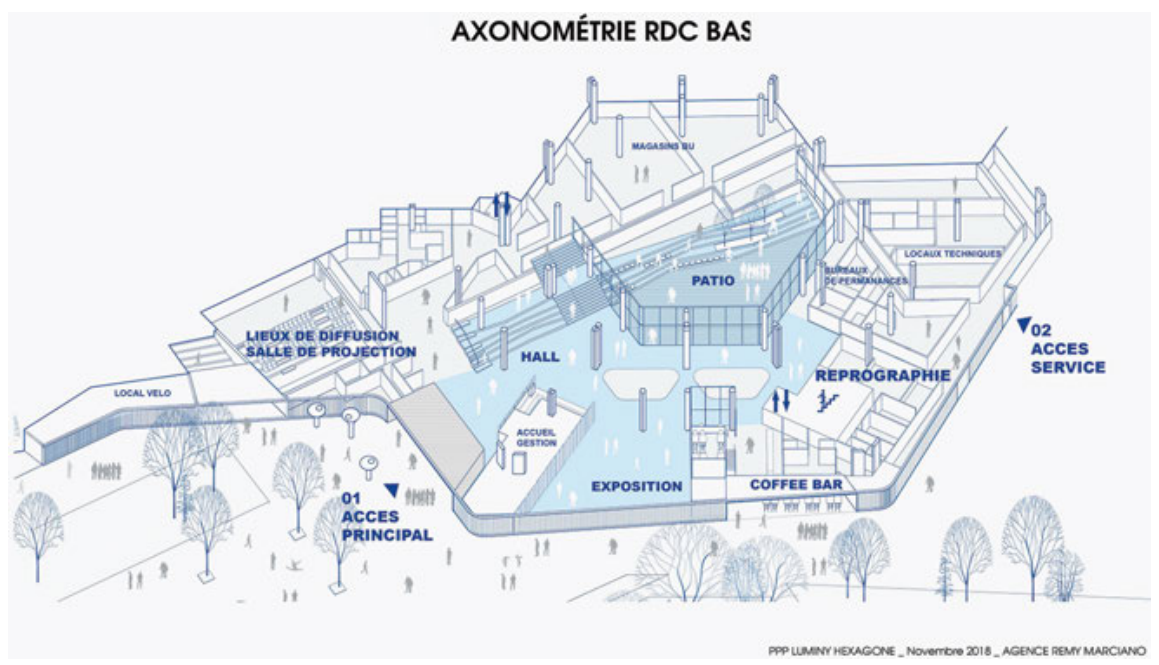

Fig. 10: The plan of the finished Hexagon project. (c) Marciano Architecture.

encourage students to take ownership of the building and enjoy the natural continuity of a generous landscape at the gates of the Calanques (Figure 11).

The design emphasises that the Hexagon is a place which can be explored with many ways to walk through the building at different levels. The entrance is reached from a forecourt, which is an extension of the central walkway. It continues in a series of terraces arranged on the natural slope of the site (Figure 10). A walk from the forecourt level allows one to walk through the open space on the ground floor, or to go out onto the central patio to reach level one on the same level as the upper part of the grounds. The secondary hall is a second access that provides a simpler connection from the south of the campus.

Because of the building's open and criss-crossing character, it offers a path through the entire campus. To study, research, meet, share, create, relax and build one's social life through diversified paths in the building, such is the goal of the spaces provided. The routes specific to students and those of the public are designed to allow for encounters but also to avoid inappropriate crossflows.

Its porous façades, like the limestone rocks of the Calanques, composed of white sunbreakers with a vertical rhythm, converse directly with the exceptional nature of Luminy. The sunbreakers are positioned and orientated according to the course of the sun. Metal mesh made of perforated aluminium is used. A peripheral window ensures a constant connection between the library and the landscape. Large frames provide a privileged and connecting relationship with the views of the Calanques (Figure 11). 
Open to the learning and exchange modes of today and tomorrow, the spaces are adapted to new learning behaviours including nomadic study, e-learning and MOOCs, particularly in relation to the use of digital technologies. The Library and Learning Centre offers unique spaces, which adapt not only to different ways of studying and different postures, but also to the climate, through the patio and terraces. Different group sizes are accommodated with rooms for people working in teams or support bubbles. Bubble rooms are small glass rooms where one can isolate oneself to work while remaining visually connected with others. They are extremely popular with students, and the glass façades make it possible to maintain transparency in the spaces and to benefit from natural lighting while providing users with the calm they need to concentrate. The rooms are available in sizes adapted to the use and location and could be installed externally to offer other work configurations in connection with the landscape. The university library, open to a $360^{\circ}$ view of the landscape, offers a high quality of comfort with consultation areas benefiting from natural light shaded by the sunbreakers and a terrace for outdoor reading enthusiasts!

Flexibility was a keynote and the Hexagon's arrangement was designed to offer possibilities for adaptation and evolution and was intended to mediate changing approaches to learning and the dissemination of knowledge in multiple scenarios. The idea is that all users can organise and adapt the spaces to suit their individual needs and ways of working. The Library and Learning Centre is designed to be flexible both inside and out, enabling changes to be accommodated and guaranteeing an evolving future for the building. The ability to move equipment around provides flexibility throughout the day, making it possible to adapt to the rhythms of students, researchers and administrative staff, and to offer access to certain parts of the building 24 hours each day. Functions have been compartmentalised to avoid the constraint of using the entire building. The Hexagon is a success for the campus and, according to AMU, a success with users.

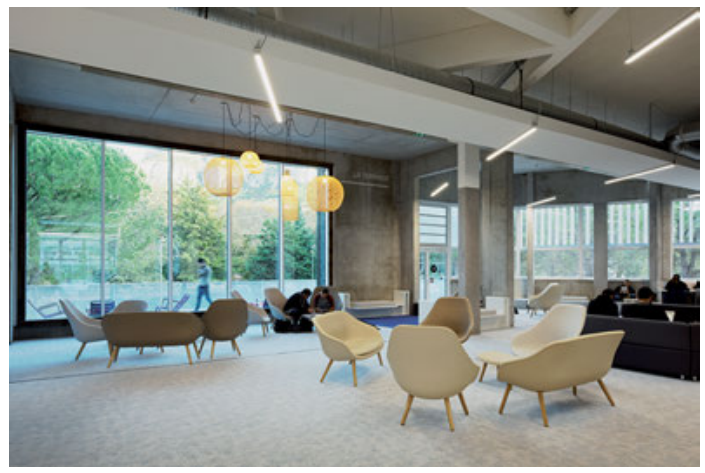

Fig. 11: Informal space in the library, with terrace at the back. (C) Takuji Shimmura. 


\section{Showcase for the Campus}

Facing the central walkway, the Library and Learning Centre forms a new heart for the campus, connecting its component parts. The porous building, punctuated by large windows, tells the story of a relationship with the site and the large area of the Calanques, with many framed views of the landscape and layers that reveal the richness of activities. It is welcoming, offers multiple entrances, and is ensconced in the surrounding landscape. The façades of the building, through the stacking of levels emphasised by successive and rhythmic vertical elements, suggest the shelves of a large library, a subtle reference to the use of the building (Figure 12). The varieties of seating indoors and the outdoor spaces provide opportunities to meet and exchange ideas in a place that encourages concentration and imagination.

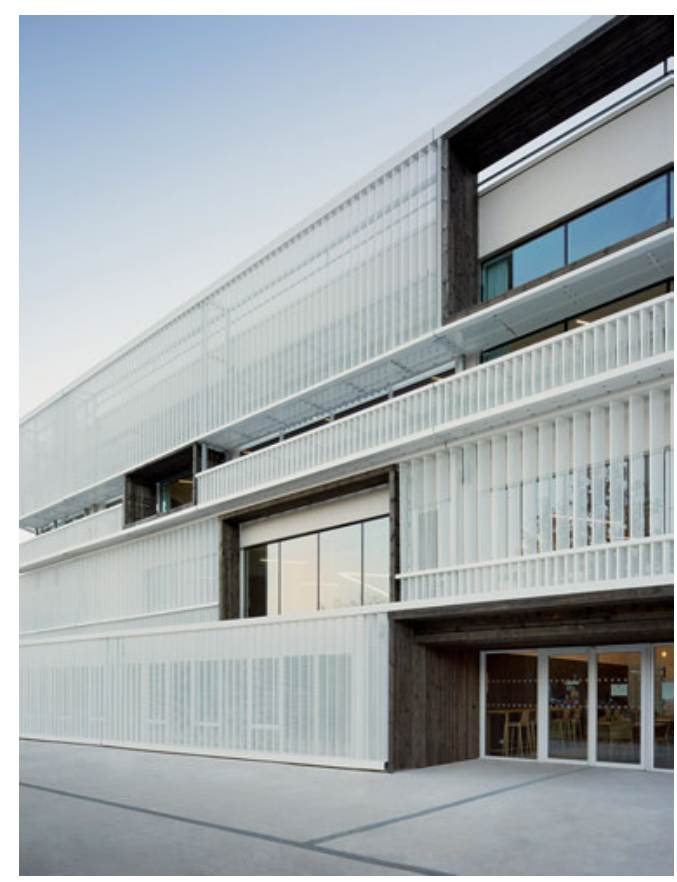

Fig. 12: Front detail view.

(c) Takuji Shimmura.

The design fits into the topography of the land on which the Hexagon building was built and is staged and integrated into the landscape. The stratification evokes both the landscape into which it is integrated and the different entities of the university and their roles in sharing knowledge and culture. The Hexagon, the heart of the Luminy campus, becomes a connected building, as much by its integration as by its technology. 
The Hexagon has regained its status as a landmark and focal point on the campus as a:

- physical expression recreating a relationship with the topography and the different levels and accesses to the site, and

- symbol whose design while strong, dynamic and fluid, reveals generous, desirable and luminous spaces.

\section{Conclusion}

The Hexagon had gradually lost its function as the heart of the campus despite its strategic position at the centre of the site. The new designed spaces offer numerous possibilities for use, development, evolution and occupation by students or researchers. The decision was taken to amalgamate several spaces and to increase the surface area of some of them. The ground floor offers from the entrance an open space with a volume high enough and spacious enough to accommodate multiple types of events. The area is connected to the sequence of the forecourt, entrance hall, exhibition room and patio.

Through a complete reconfiguration, the Hexagon has become a showcase for innovation and exchange, an extraordinary place in which students want to work, collaborate, share and forge their destiny. Spaces conceived as flexible and evolving spatially and pedagogically have become attractive places of innovation and a driving force for the whole campus. The Hexagon creates links between the building, the context and campus activities and asserts its status as a structural element weaving new associations between the landscape and the building, inside and outside, skin and structure, and the location and its flexibility.

A year and a half after its restoration, the Hexagon has found its audience. Not only students, teachers and university staff, but also hikers from the nearby park, tourists and users of the site's sports facilities come to visit and use it. A real dynamic has been set up between the various services available within the Hexagon. Workshops initially set up by the library around bibliographic tools and soft skills like public speaking, making successful presentations, creating a poster to present one's research and organising one's ideas with mind-mapping have expanded in collaboration with the Counselling Service and include creating and updating one's CV and writing a cover letter along with topics like introduction to LaTeX and website creation.

From an architectural point of view, the building is a real success. The architect was able to make the most of the Hexagon's assets including its surface area, its strategic location, through site integration and the surrounding landscape, 
through further enhancement and emphasis. At the same time the weaknesses that time had revealed, including the lack of natural light in central spaces and complexity in the circulation of spaces, were solved by new inclusions like the patio and diverse paths through the building with differing levels. Perhaps the only regret is that the frescoes which covered the building while it was no longer in use could not be preserved. They remain in memory, and the functional efficiency of the building and the pleasure of using it daily make up for their loss. The Hexagon has embarked on a second phase in its life and the people who work in it will do their absolute best to ensure that it is exploited to the full.

\section{References}

Aix-Marseille Université. 2018. Aix-Marseille Université: Des Campus Rénovés aux Standards Internationaux: Inauguration de l'Hexagone. Marseille. https://www.univ-amu.fr/system/ files/2019-11/DIRCOM-dp_inauguration_hexagone.pdf

Feil, Tanja. 2020. "Schwungvolles Sechseck: Learning Center in Marseille (F)." db, Deutsche Bauzeitung (9), 12.04.2020. https://www.db-bauzeitung.de/db-metamorphose/learningcenter-marseille-remy-marciano/

Schoof, Jakob. 2019. "Dance of the Hexagon: University Library by Rémy Marciano in Marseille." https://www.detail-online.com/article/dance-of-the-hexagon-university-library-by-remymarciano-in-marseille-34622/

Shimmura, Takuji. 2019. "Verwandlung eines Hexagons: Umbau von Rèmy Marciano in Marseille.” BauNetz, 16.04.2019. https://www.baunetz.de/meldungen/ Meldungen-Umbau_von_Remy_Marciano_in_Marseille_6466175.html

Wu, Cecile. 2019. “Hexagone: Luminy Campus Heart." https://www.univ-amu.fr/en/public/ hexagone-luminy-campus-heart 